\title{
A Multimedia Web GIS Portal for Promotion of Tourism in Kenya
}

\author{
Charles M. Muriuki, Benson Kenduiywo \\ Department of Geomatic Engineering and Geospatial Information System (GEGIS), Jomo Kenyatta University of Agriculture and \\ Technology (JKUAT), Nairobi, Kenya \\ Email: charlesmuriuki@jkuat.ac.ke
}

How to cite this paper: Muriuki, C.M. and Kenduiywo, B. (2021) A Multimedia Web GIS Portal for Promotion of Tourism in Kenya. Journal of Geographic Information System, 13, 19-35. https://doi.org/10.4236/jgis.2021.131002

Received: December 3, 2020

Accepted: February 1, 2021

Published: February 4, 2021

Copyright ( 2021 by author(s) and Scientific Research Publishing Inc. This work is licensed under the Creative Commons Attribution International License (CC BY 4.0).

http://creativecommons.org/licenses/by/4.0/

(c) (i) Open Access

\begin{abstract}
Tourism is a major foreign exchange earner in Kenya contributing to $10 \%$ of the gross domestic product (GDP). Whereas Kenyan government strives to boost its GDP through improved arrivals, lack of effective tourism marketing strategies hinders growth in tourist arrivals in Kenya. To advertise and market the untold wealth of tourist destinations, the government utilizes campaigns through print and electronic media, which are expensive and limited in updating. This study addresses the gap by designing a web Geographic Information System (GIS) portal for marketing and promotion of tourism. To realize this a multimedia GIS database was created using PostgreSQL/PostGIS software to store spatial and multimedia tourism data, while itinerary planning tools were designed using Dijkstra algorithm and Travelling Salesman Problem (TSP) approach. The result was a web GIS portal interface containing tourist information enhanced with text and/or video/audio descriptions. Facebook advertisement was used to popularize the tourism products available in Kenya through visitor engagements as well as directing traffic to the portal fast and inexpensively.
\end{abstract}

\section{Keywords}

Dijkstra, Travelling Salesman Problem Approach, Trip Planning, GIS in Travel, Optimal Path

\section{Introduction}

Tourism is a major foreign income generator and its contribution to global economy is remarkable as it plays a major role in enhancing a country's gross domestic product (GDP) [1]. It is a dynamic and valuable sector of economy that is gainful if natural, cultural and historical wealth is well managed [2]. 
Global tourism supported 319 million jobs equivalent to $10 \%$ of total global employment in 2018 [3]. However, African region is yet to reach full potential because of the inability to progressively attract local and international tourists. This is caused by the failure to adapt and innovate the tourism industry in line with global trends and the changing world leading to slow growth in tourist destinations [4]. Kenya's vision 2030 identifies tourism as the leading sector in economic pillar and aims to position the country as one destination that offers high end and diverse visitor package [5]. In 2017, Kenya earned approximately Ksh 157 billion in receipts from approximately 2 million arrivals; this was Ksh 43 billion short of midterm II (2013-2017) projection which anticipated a target of 200 billion in receipts from 3 million tourist arrivals [6] [7]. Kenya therefore needs to employ effective methods of tourism marketing in order to realize this goal and become a premier tourist destination in the region.

Tourist facilities are geographically distributed in the real world, on the other hand Geographical Information System (GIS) is used to capture their location and visualize this information on a web GIS platform [8]. According to Abdulhamid \& Usman (2014) tourists need extensive information about their intended destination [9]. In addition, tourists require good guidance and navigation around their destination of choice [10]. In this respect, GIS has the capability to store spatial and attribute components of attraction sites as well as visualize them on the internet. With its strength in spatial queries, GIS supports decision making processes and contributes immensely to various applications like information management where ordinary maps are converted into smart maps [11].

Galelekile (2020) describes destination marketing as a way of communicating destination's value proposition to give reason why people should visit your attraction [12]. In support of this, studies have shown that prior information on a destination helps to promote tourism by way of influencing tourist's decision making [13]. Moreover, over $80 \%$ of users search for information on products and services prior to making a purchase, travel being an example [14]. Kaylo, Juliane Katuse (2013) noted that before travel decision is made, a mental image of the destination is formed [15]. However, a research by M. Ndivo \& N. Waudo (2012) to investigate the level of attractiveness for Kenya's tourist destinations revealed that out of 47 destinations, only $46.8 \%$ of these destinations were known and considered as possible holiday destination [16]. The authors continue to argue that despite Kenya's attractions spread throughout the country, tourism is mainly concentrated in coastal beaches and a few National Parks and Reserves. This was attributed to limited information about tourist activities and lack of sufficient travel information in the country [16].

Kenya Tourist Board (KTB) is the body mandated by government to develop, implement and coordinate national tourism marketing [17]. In its endeavor to market Kenya's tourism globally, KTB depends heavily on established foreign based tourist offices in various countries in Europe, Asia and the USA to achieve global visibility [18]. Other methods employed to capture local market include electronic (i.e. radio and TV) and print media (i.e. newspapers and magazines) 
all of which are expensive to sustain and reach a relatively small audience [19] [20]. A study by Philip O. Obiero refers to these methods as traditional methods and distinguishes them from the non-traditional methods which employ online marketing [21]. The study also recommended the rebranding and upgrading of attraction sites, using both traditional and non-traditional marketing strategies to make them more visible in the global market.

With the emergence of mobile and Internet technology, Information and Communication Technology (ICT) is used to share destination information to prospective tourists across the world [22]. This is becoming common and more popular in many countries because information technology can reduce cost of doing business and enhance efficiency [23]. For efficient tourism marketing, information systems will require GIS to deliver spatial-travel information on the internet [24]. The resultant architecture contains a web GIS server and a client side application. Such model is a web GIS application that supports a graphical user interface, implements GIS analysis and facilitates data visualization procedures cheaply [25].

A number of countries have embraced a full-fledged web GIS system to promote tourism. An example is the Nigeria open source GIS used to create a web GIS platform to plan, manage and promote tourism [26]. Another study by Sharma (2016) developed a similar platform to aid tourists in Assam district, India [27]. Being a web based application, it targeted wider audience and implemented updates regularly. A similar study used multimedia data (i.e. video, audio, and text) [28] combined with spatial data to form web GIS. Video files, audio and spatial data were combined with internet technology to form multimedia web GIS application that provided powerful tools to solve spatial query solutions online [29] [30]. However, these systems lacked trip planning capabilities useful for trip personalization.

For tourists, trip planning involves visualizing, exploring and sampling of available tourist activities and routes with a view to gaining awareness about tourist destinations they intend to visit [31]. Information on proximity is key to travelers as it forms a clear picture of destination accessibility and the surroundings [32]. Tourists can select preferred destinations, choose favorite accommodation, decide which routes to take and more importantly generate sequence of destinations points of interest in an optimal order [33] [34]. Our proposed system employs Travelling Salesman Problem (TSP) optimization algorithm using GIS, as a decision tool to determine shortest routes [35]. It helps the visitors to plan their itineraries before they reach their destinations making it easier for them to decide where to visit and what to see [36] [37]. This enables individual attractions sites to gain equal visibility and ensures country wide competitiveness [8]. Less known and unique products have a chance to be discovered.

World over, the internet technology and e-commerce have helped improve online marketing by using Business to Consumer (B2C) transactions with tourism benefiting a great deal [38]. Facebook is an effective communication channel 
mainly used to raise brand awareness and creating engagement with the users. According to Facebook Newsroom (2019) there were 2.38 billion active users by $31^{\text {st }}$ March 2018 [39]. Facebook allows destinations to manage their image as well as sharing content. It is interactive, dynamic and connects people with similar interests [40]. In tourism marketing Facebook offers travel destinations the ability to showcase their brands to prospective visitors, engage directly with clients, in addition to creating a branded experiences through Facebook advertisements.

\section{Materials and Methods}

\subsection{Study Area}

Kenya was chosen as study area because of its diverse tourist attraction sites. Moreover, the country lacks a web enabled web GIS platform for planning and marketing tourism. Kenya as shown in Figure 1 is an Eastern Africa country and spans approximately $582,000 \mathrm{~km}^{2}$ in land mass where $7.5 \%$ of the land surface $\left(43,600 \mathrm{~km}^{2}\right)$ is covered by National parks and National reserves that offer touristic activities. There are 59 scenic national parks and reserves, 4 marine parks, private reserves and game ranches across the country. With palm fringed shoreline of $480 \mathrm{~km}$ that is home to beautiful cliffs and magnificent sandy beaches, Kenya coastline is ideal for water sports and deep sea fishing. The Great Rift Valley has an approximate width of $80 \mathrm{~km}$ and divides the country down the length into two, it is home to most spectacular sceneries like the escarpments, lakes, hot springs, geysers, extinct and active volcanoes.

\subsection{Methods}

Figure 2 summarizes approaches we adopted to develop a multimedia GIS web application. GIS shapefiles were prepared in QGIS software [41] for purposes of

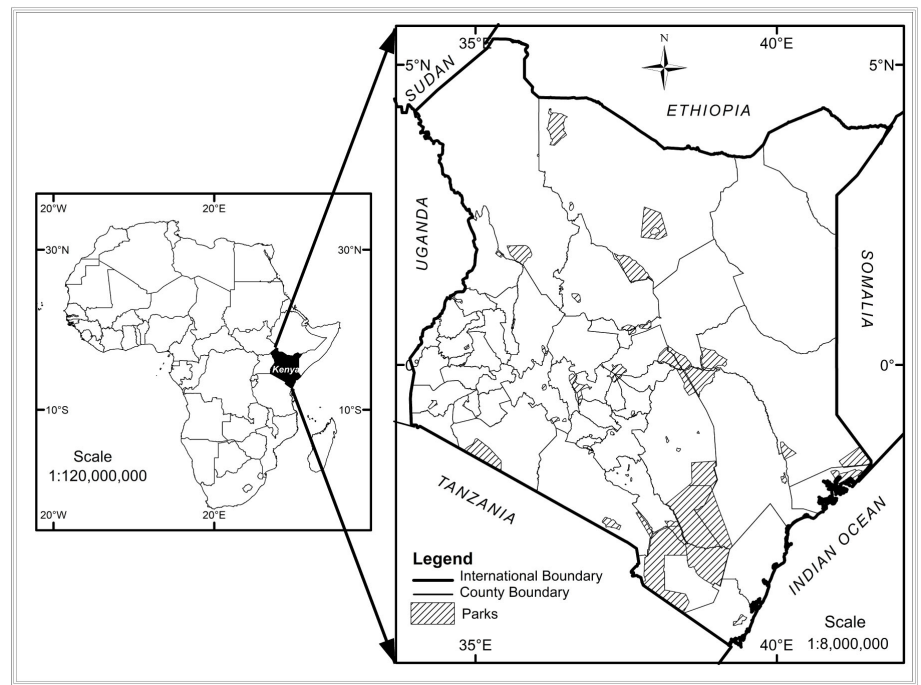

Figure 1. A map of the study area showing touristic attractions in Kenya. (Data source: World Resource Institute). 


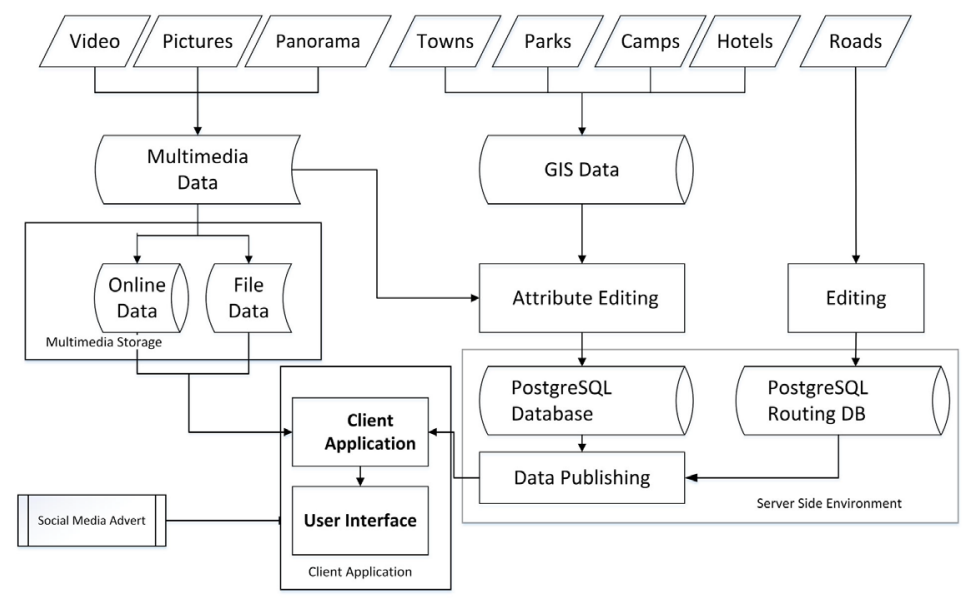

Figure 2. Conceptual framework adopted in the study.

creating a GIS database. Multimedia files were grouped into two categories namely; pictures and videos. Videos described activities in parks and were saved in an online video database while pictures representing what to see in the attraction were stored in a folder together with the index html. GIS routing database was created using PostgreSQL Software [42] and published using Geoserver [43] web server, while Leaflet [44] client application programming interface (API) was used to create an interactive map.

\subsection{Needs Assessment and User Requirements}

In order to understand tourism products in Kenya, a survey was conducted using 220 structured questionnaires distributed using random sampling to Kenyan residents and foreign visitors. The survey was aimed at assessing any gaps or trends in terms of popularity of tourism products as well as to decide on a convenient marketing method. Also examined were the preferred methods of trip planning and how travel experiences are shared within the social media. To get a proportionate representation of the targeted respondents, the study used Cochran's standard sample size calculation formula designed for infinite population as shown in Equation (1).

$$
N=\frac{z^{2} p q}{e^{2}}
$$

where $N$ is the sample size.

$Z$ is confidence, $p$ sample proportion, $q=1-p, N_{0}$ is population size, and $e$ is Margin of error. A second survey for all the travels and tour companies was administered with a sample size of 98 questionnaires determined using Cochran's second formula as shown in Equation (2) for finite population [45].

Sample size,

$$
N=\frac{\frac{z^{2} p(1-p)}{e^{2}}}{1+\left(\frac{z^{2} p(1-p)}{e^{2} N_{0}}\right)}
$$




\subsection{Data Acquisition}

Excerpts and derived Openstreetmap (OSM) roads data for Kenya were downloaded from Geofabrik [46] available for free. Other open and free data sets included Kenya Parks, Kenya Hotels, Kenya Towns, and Kenya Campsites all acquired from World Resource Institute [47]. Selected free to use videos and pictures were downloaded from the Kenya wildlife service website [48] all covered under creative commons attribution license.

\subsection{Data Preparation}

It involved two processes, first was preprocessing and editing of all the GIS data in QGIS software and second was creation of Network dataset. Kenya roads data was edited in QGIS to eliminate unwanted fields and creating new fields relevant to this study. Eventually 57 columns for Kenya roads attribute table were reduced to 7 fields after editing. Kenya hotels attribute table was edited to introduce new field to carry Uniform Resource Locator (URL) for hotels websites. This field links Kenya hotels and camps Shapefiles to their respective online websites. Similar attribute editing was done for Kenya parks Shapefile which carried two fields to hold URLs for videos and photographs describing activities in parks and other attractions. Photographs describing parks were placed in a common folder with the index html, while videos were freely hosted in Vimeo database to be retrieved online using URL provided in the attribute table.

\subsection{Database Design}

PostgresSQL [49] was used to create spatially enabled database using the graphical PgAdmin 4 [42] utility. Edited Shapefiles for Kenya hotels and camps, Kenya parks, and Kenya towns were imported into PostGIS database using a pgShapeloader utility. pgRouting extension [50] was used to create network dataset for roads where fields to hold routing characteristics were created. Roads topology was established creating nodes and arcs in order to achieve a routable roads dataset. The Shapefiles were exported to Geoserver application [43] for publishing. This is an open source web mapping server used to create workspace and subsequently publishing data online using Web browser.

\subsection{Network Routing Using Dijkstra Algorithm}

Dijkstra algorithm was used to model Roads data as a graph with weighted edges suitable for finding shortest paths between two vertices [51]. Graph theory as shown in Equation (3) forms basis for weighted graphs and their applications [52] e.g. network analysis where sets of vertices $(V)$ and edges $(E)$ are processed using Dijkstra algorithm. Inputs for the graph includes weighted $(w)$ graphs representing connected vertices and edges with some numerical values attached to the edges to represent distances [11] i.e.

$$
\text { Graph: } G=(V, E, w)
$$


where $V=\left\{v_{1}, v_{2}, \cdots, v_{n}\right\}, E=\left\{e_{1}, e_{2}, \cdots, e_{m}\right\}$ and $w=\left\{w_{1}, w_{2}, \cdots, w_{m}\right\}$.

GIS graphs are geo-referenced to provide vertices that have geographically defined coordinates [11]. Our roads data were topologically modelled therefore had the correct geometry for the network analysis. Data was represented as vertices and a numerical value assigned to the edges that describes the entire length of path. The weight of a path is the sum of weights of all edges it contains [11]. In this study network was modelled using roads database to obtain minimum cost between source node and destination node to form an optimal path distances for roads network. Given graph equation (Equation (3)) for source node $u_{0} \in V$, shortest path and distance from a node $u$ to $v$ given by $\operatorname{dist}(u, v)$ for all $v \in V$, carries minimum weight of all possible paths with source $u$ and destination $v$. The distance from $u_{0}$ to $\bar{S}$ is given by formula in Equation (4) where $\bar{S}$ denotes $V$ - $S$ and that $u_{0} \in \bar{S}$

$$
\operatorname{dist}\left(u_{0}, \bar{S}\right)=\min _{u \in S, v \in \bar{S}}\left\{d\left(u_{0}, u\right)+w(u v)\right\}
$$

\subsection{Traveling Salesman Problem Algorithm}

This algorithm was used to find the most optimal route through a set of points located spatially in space along roads data. It follows the Hamiltonian principle which states that a tour starts and ends at the same point, and all locations are visited once and only once and in the best order, with an optimally minimal overall travelled distance [53]. Its aim in tourism is to select a planned sequence of tourist destination points and find an optimal route with minimum distance generated along the road network [36].

\subsection{System Implementation}

The application was built using Leaflet API [44] which is a client side programing language. This is an open source JavaScript library for making interactive maps. Leaflet API pulls shapefiles from Geo-server workspace and displays them as a GeoJSON files on a web browser. It was used to style and display the layer properties for all layers. URLs in respective attribute tables helped to link data to online resource where videos and other information can be explored online. Route optimization was implemented using open source GraphHopper routing API [54], the user selects points of interest to be visited and the functionality creates an itinerary of ordered points in sequence of visit. Shortest routes between points on the map were implemented by use of movable marker that contained source and second marker for destination points. Other functionality included finding closest facilities from selected location, slider tool was used to specify the radius of coverage to select nearest facilities. The user interface provides tools to explore the web GIS functionalities and allows users to interact with tourist data. A search bar was provided to search and display data in various layers of the web GIS application. Facebook $\mathrm{Ad}^{\text {Tw }}$ was prepared targeting audience living in the USA and in particular, Los Angeles, aged between 30 - 65 years. USA being one of the world's best performing outbound market, remains 
Kenya's leading tourism source markets with market share of $11.8 \%$ as at December 2017 [55]. A link was provided in Facebook Advertisement to direct visitors to the web portal for purposes of sampling Kenya's tourism products to create awareness. Kenya has an opportunity to expand further and capture a bigger share away from the competitors by creating more awareness to increase arrivals [56]. The advertisement was used to engage audience and popularize the site with the intention to increase traffic to our portal.

\section{Results}

\subsection{Questionnaire Results}

Figure 3 represents results of a survey conducted to assess the need for a tourism marketing portal. Findings from the survey indicate that Kenyan citizens and foreign visitors aged between 20 and 70 years responded, where $51 \%$ of respondents were female and $49 \%$ were male. The survey showed that $60 \%$ of the respondents had previously visited an attraction site in Kenya while $40 \%$ had not visited any tourist attraction. From the study wildlife tourism was found to be the most preferred of all the tourist products offered in Kenya followed closely

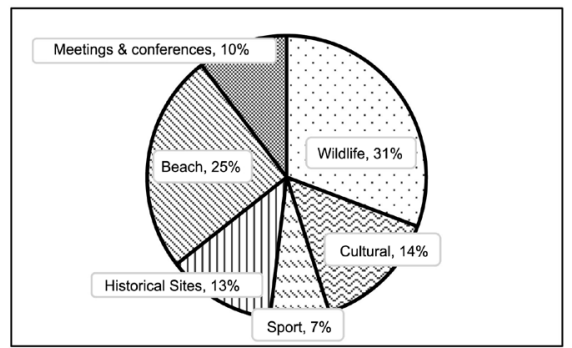

(a)

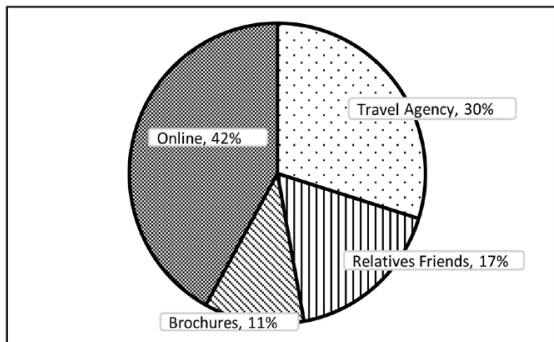

(c)

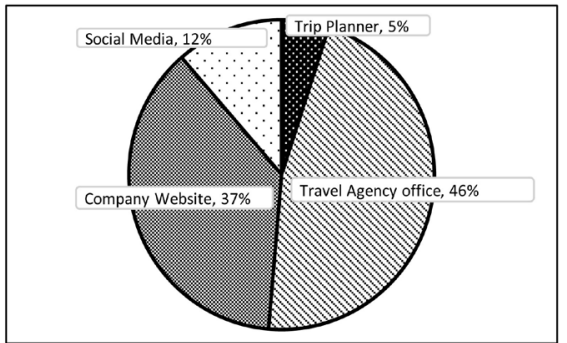

(e)

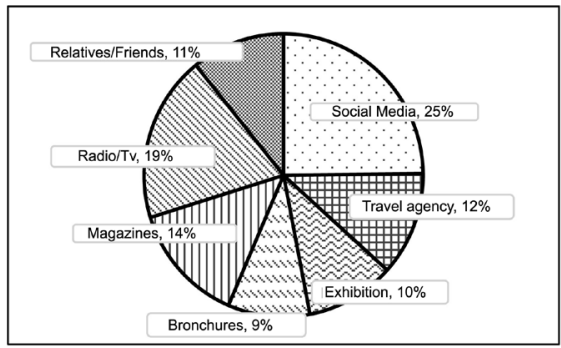

(b)

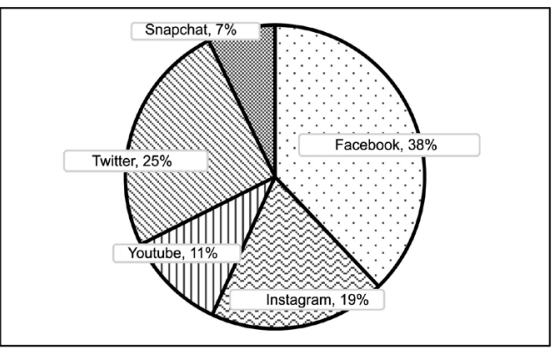

(d)

Figure 3. Needs assessment survey results: (a) Preferred tourist products; (b) Marketing methods; (c) Preferred trip planning methods; (d) Preferred social media content sharing method; (e) Tourist booking methods. 
by activities in the coastal beaches (Figure 3(a)). The results further indicated that internet is the leading source of tourist information, however traditional methods like electronic media, print media, exhibitions and travel agencies also play a significant role in providing tourism information for Kenya's destination (Figure 3(b)). Further, the survey revealed that close to half of the respondents preferred planning their trips online while the remaining proportion preferred using other methods as shown in Figure 3(c). However, a survey on tours and travel companies revealed that $46 \%$ of the bookings were done through travel offices while $37 \%$ was done through the company websites (Figure 3(e)). This means that although a large proportion of travelers preferred planning trips online, tourist operators had not fully embraced online planning technology and were still using travel booking offices. Regarding sharing of content, Facebook was found to be the most preferred online method of sharing holiday experience followed closely by Twitter as shown in Figure 3(d). Facebook was therefore the most effective methods of reaching the potential clients over social media.

\subsection{Kenya Tourist Facilities}

Figure 4 represents Kenya web GIS map showing parks, hotels, road network, and towns. This is an interactive map that displays activities and brands in the attraction sites. Multimedia data, in form of Videos, audio, and websites, were linked to spatial data to provide more detailed information about the products available. Tools for querying data, proximity were provided, these included Search tool, Select tool and closest facilities.

\subsection{Network Routing}

Figure 5 represents a routable road network system developed representing roads in Kenya. Shortest distances from origin to destinations were established with their distances displayed. The routes and closest facilities are computed along the roads using the Dijkstra algorithm. Minimized distances between origin and destination are selected and displayed on map.

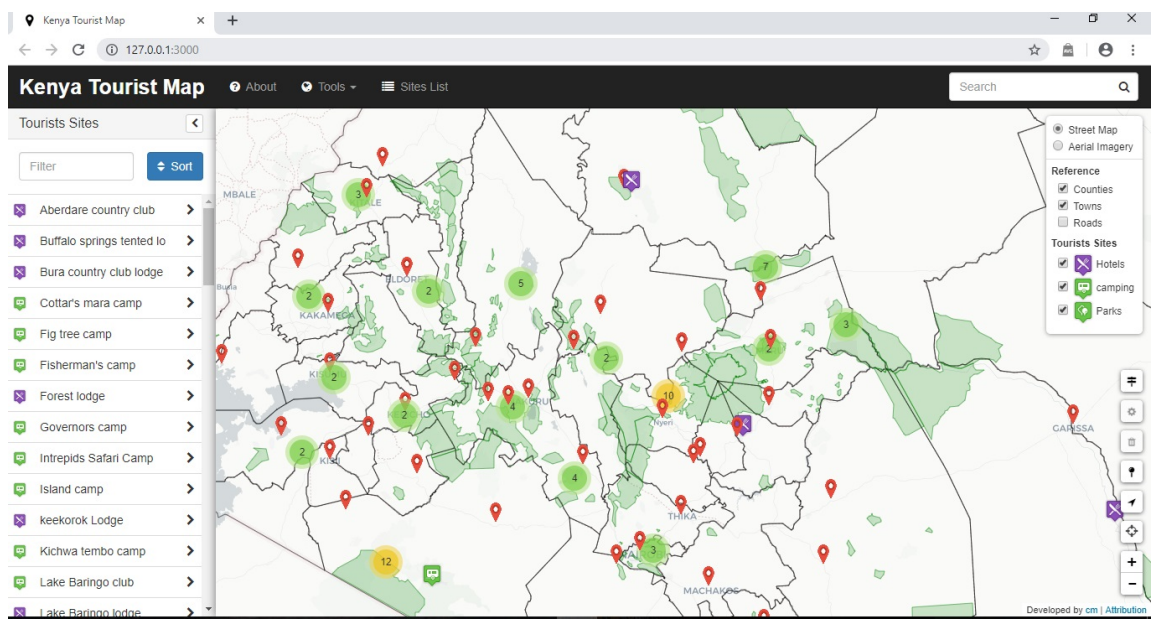

Figure 4. Kenya tourist attraction sites on a web GIS application. 


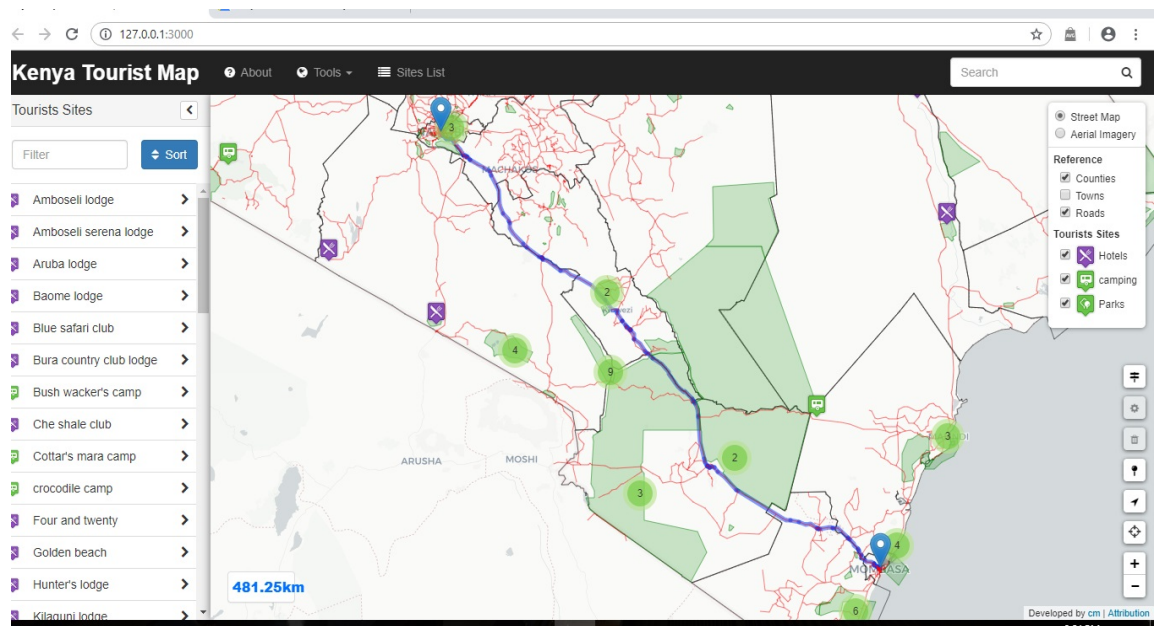

Figure 5. Map showing shortest routes between two selected nodes.

\subsection{Web GIS Itinerary}

GIS was used to recommend optimal routes and itinerary planning using TSP along Kenya Roads network. Distances are displayed in kilometers, representing the entire length of the itinerary along the roads through a set of selected points. Points to be visited were ordered sequentially for entire travel plan as indicated in Figure 6. Customized tour plan consisting of least distance between the multiple tourists destinations are displayed spatially on a map.

\subsection{Marketing Tourism Web GIS Platform Using Facebook Advertisement}

Figure 7 contains results from Facebook advertisement after running a promotion of Kenya tourist web GIS application through engagement. The advertisement targeted travel groups within $40 \mathrm{~km}$ from Los Angeles city, USA, running for one week starting from $8^{\text {th }}$ February to $15^{\text {th }}$ February 2019. Results of the insight indicate that a total of 342 people were reached with 59 engagements.

\section{Discussion}

Kenya is endowed with plenty of scenic natural landscape, national parks, reserves, Museums, sports tourism, conferencing facilities, nature trails, beaches and a rich diverse culture. The aim of the study was to gather all these tourism products and services into one central point using web GIS for purposes of creating awareness and marketing. An inventory of Kenya's tourist sites with their activities represented using multimedia was created. A web GIS was developed to display the attraction sites in their respective geographical locations while attribute and multimedia data was used to provide more information about the destinations' appeal such as; brands, services available, activities, opening times, and charges. This content creates awareness and allows visitors to explore various alternatives to help in making travel choices. The main aim was to raise the status of appeal for attraction sites and to reverse the impression that 


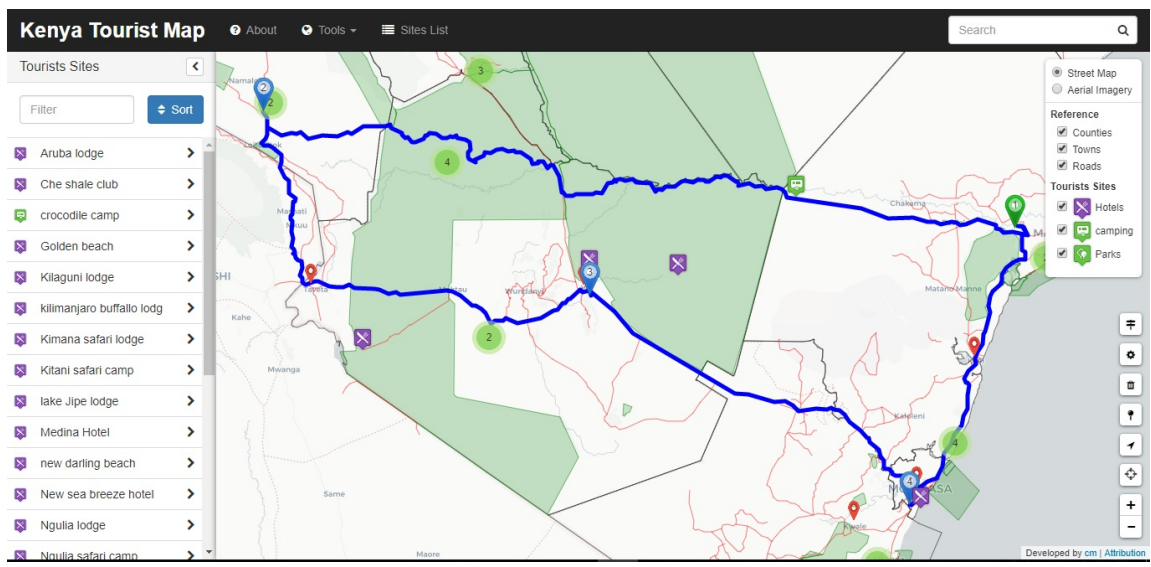

Figure 6. Map showing optimal routes for an itinerary planning.

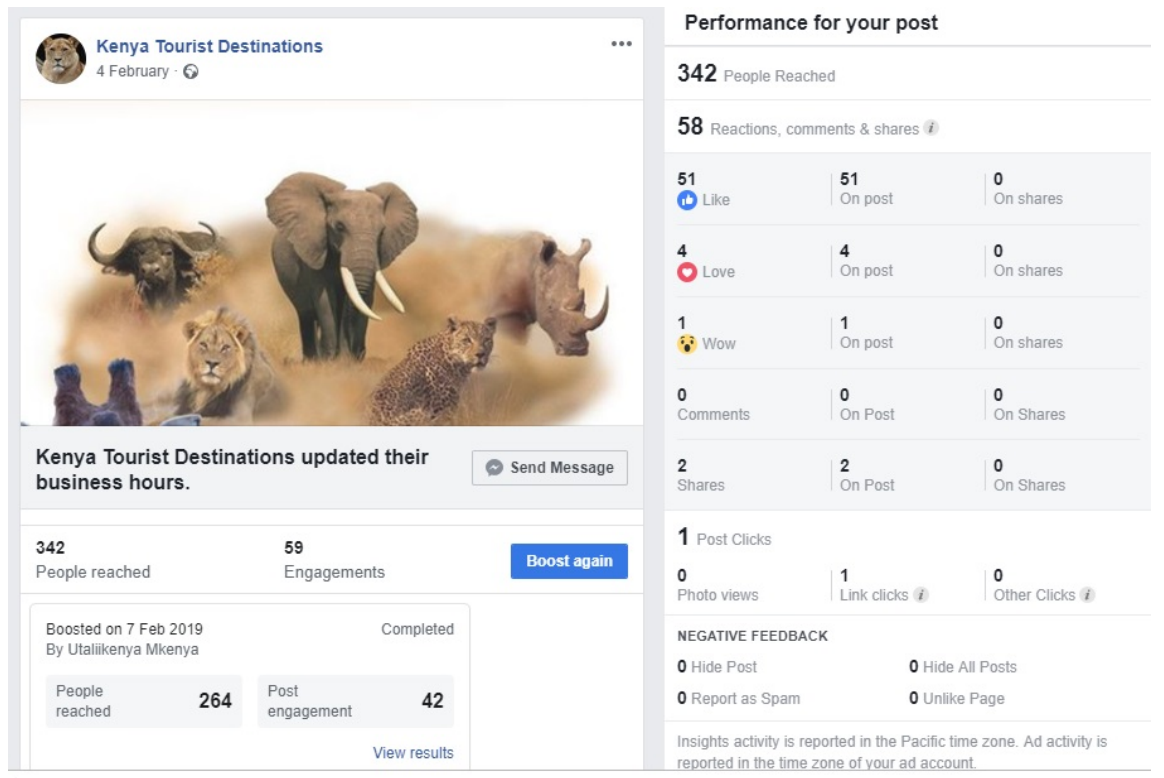

Figure 7. Results for one week's performance of the Facebook Advertisement, extracted from Facebook insight.

tourism in Kenya only revolves around the coastal beaches and a few wildlife parks [16] [57].

The developed web GIS platform provides enough content for all attractions sites to gain equal visibility. Therefore, less known attraction sites with unique products have a chance to be discovered and considered for visit. In line with the government's planned decongestion programme of some highly visited attraction sites, this is a modest contribution to policy makers to deliberately innovate unique products in alternative centers and use our portal for marketing the sites [4].

Studies have shown that, information presented using different formats through visualization is captured well by the human memory [28]. Our portal previews what is offered at every attraction sites and helps the visitor to plan a sequence of ordered destination points that forms an itinerary. This process is 
guided by the individual interests and knowledge acquired about the destination, consequently making customized trips more satisfying than the usual pre-determined tour circuits which are centered only on the prominent tourist regions [58]. Our results described for the first time in Kenya, a self-generated travel plan informed by travel interests and cognitive content.

Similar studies have been done, an example being tourism in public forest [59] which implemented shortest routes to manage traffic within a forest, however in our study particular attention was paid to implementation of customized trips. Like the web enabled GIS navigation system [60], our study also provided visitors with information about nearest facilities including accommodation, restaurants, places of interest and generates the most feasible routes.

Kenya tourism Stakeholders don't have a dedicated portal to display tourist information but instead they heavily rely on Google maps [61] and Google earth [62]. Although this is a great way to visualize data and finding shortest routes, it lacks the detailed customized content to promote brands in a destination, enough to place every attraction sites on the same level of competitiveness. They are generic and are not focused in a thematic area. Searching data is however cumbersome as it involves browsing the deeply hyperlinked textual information. Our tourist information on the other hand is a thematic web GIS map customized as one unified product placed in a central inventory to guarantee convenient and easy searching of tourism data in one place. Facebook page was created to advertise tourism products through engagements with visitors, this allows deeper understanding of brands packaged in various individual attraction sites. To achieve this, a link carrying the web portal's URL was provided in Facebook page to connect visitors to the portal. A similar link carrying Facebook page URL was provided in the web portal to connect with the Facebook page. This mode of advertisement is cheap and fast enough to reach many users worldwide in a short time. Findings from our advertisement illustrate that, this is a convenient method that reached audience with targeted travel interests.

However one limitation, encountered in the study was that our Facebook advertisement ran for 7 days, but it was realized that advertisements are a process that requires continuous monitoring and active engagement in order to sustain the needs of social media clients. The study recommends that the country should invest more on social media advertisement in order to gain more visibility in the world market as well as generating continuous engagement with the audience.

\section{Conclusions}

Advent of web Geographical Information System (GIS) has made possible storage, analysis and dissemination of spatial data over the internet. We tap into this potential in order to design a web GIS tool to enable route planning and promotion of tourism in Kenya for the first time. A multimedia GIS database representing tourism activities and attraction sites in Kenya was created using free and open source software. Our study demonstrated that for a country to 
make impact on tourism growth, a comprehensive tourism inventory is created to provide destination information to potential visitors. Geospatial functionalities combined with tourism information packaged in audio and videos were used to show activities in the parks as well as facilities in hotel rooms. This inventory was customized to create awareness and sell the image of the site for marketing and promotion of the destination. To share this data, a GIS web server functionality was used for publishing the content online. Users only required a regular web browser to interact with the system and do not need to be experts in complex GIS applications.

Our system uses route optimization technique to recommend optimal itinerary plan between multiple destinations in a GIS environment. Other Capabilities in our web GIS system included tools to query data as well as route planning that included shortest routes and optimal paths. This was implemented using Travelling Salesman Problem (TSP) and Dijkstra algorithm. Both techniques use Kenya road network dataset to provide shortest path distances between points on a map. For purposes of marketing tourism in Kenya, a Facebook advertisement Page was created to promote tourist products through visitor engagements. The results showed that Facebook with its large following can reach a large audience in a short span of time.

\section{Acknowledgements}

This research received no specific grant from any funding agency in the public, commercial, or not-for-profit sectors.

\section{Disclosure}

We declare that this manuscript is original, has not been published before and is not being currently considered for publications elsewhere. We know of no conflicts of interest associated with this publication, and there has been no significant financial support for this work that could have influenced its outcome. As a first author I confirm that the manuscript has been read and approved for submission by the $2^{\text {nd }}$ author who supervised the entire work until completion.

\section{Conflicts of Interest}

The authors declare no conflicts of interest regarding the publication of this paper.

\section{References}

[1] Khan, A., Bibi, S., Lorenzo, A., Lyu, J. and Babar, Z.U. (2020) Tourism and Development in Developing Economies: A Policy Implication Perspective. Sustainability, 12, 1-19. https://doi.org/10.3390/su12041618

[2] Kulyk, V. and Sossa, R. (2018) Determining the Tourist Attractive Regions by GIS Analysis Using Heatmaps. Geodesy and Cartography, 44, 22-27.

https://doi.org/10.3846/gac.2018.882

[3] WTTC (2019) Travel \& Tourism World Impact 2019-World. 
[4] Ministry of Tourism and Wildlife (2020) Republic of Kenya.

[5] Kippra (2017) Kenya Economic Report 2017. Sustaining Kenya's Economic Development by Deepening and Expanding Economic. Integration in the Region. 1-138.

[6] Tourism Research Institute (2018) Tourism Sector 2018.

[7] GoK (2013) Sector Plan for Tourism 2013-2017. 1-56.

[8] Thecla, A. and Chigozie, O. (2014) Designing and Developing a GIS Database for Tourism in Nigeria: The Case of Anambra State. IOSR Journal of Humanities and Social Science, 19, 109-120. https://doi.org/10.9790/0837-19108109120

[9] Abdulhamid, S.M. and Usman, G. (2014) Destination Information Management System for Tourist.

[10] Ngwira, C. and Kankhuni, Z. (2018) What Attracts Tourists to a Destination? Is It Attractions? African Journal of Hospitality, Tourism and Leisure, 7, 1-19.

[11] Ni, K., Zhang, Y.-T., et al. (2014) Shortest Path Analysis Based on Dijkstra's Algorithm in Emergency Response System. TELKOMNIKA Indonesian Journal of Electrical Engineering, 12, 3476-3482. https://doi.org/10.11591/telkomnika.v12i5.3236

[12] Galelekile, T. (2020) Destination Marketing Explained: Meaning, Trends and Challenges. https://placebrandobserver.com/destination-marketing-explained

[13] Chetthamrongchai, P. (2017) The Influence of Travel Motivation, Information Sources and Tourism Crisis on Tourists' Destination Image. Journal of Tourism \& Hospitality, 6, Article ID: 1000278. https://doi.org/10.4172/2167-0269.1000278

[14] de las Heras-Pedrosa, C., Millan-Celis, E., Iglesias-Sánchez, P.P. and Jambrino-Maldonado, C. (2020) Importance of Social Media in the Image Formation of Tourist Destinations from the Stakeholders' Perspective. Sustainability, 12, 4092. https://doi.org/10.3390/su12104092

[15] Kaylo, P. and Katuse, J. (2013) Kenya's Destination Image: Perceptions of Kenya as a Premier Destination of Africa. International Journal of Social Sciences and Entrepreneurship, 1, 654-666.

[16] Ndivo, R.M. and Waudo, J.N. (2012) Examining Kenya's Tourist Destinations? Appeal: The Perspectives of Domestic Tourism Market. Tourism and Hospitality, 1, Article ID: 1000103. https://doi.org/10.4172/2167-0269.1000103

[17] Government of Kenya (2012) Tourism Act 2012. No. 1.

[18] Tourism Research Institute (2019) Tourism Sector Performance Report.

[19] Madondo, E., Chiguvi, D. and Tadu, R. (2019) Assessment of the Effectiveness of Traditional Media for the Promotion of Tourism in This Digital Age in KwaZulu-Natal South Africa. Business \& Management Studies, 5, 36. https://doi.org/10.11114/bms.v5i4.4598

[20] Vinaya Kumar, C.M. and Mehrota, S. (2018) Print vs. Online Advertising-Impact on Buying Behavior of Youth. Global Media Journal, 16, 1-3.

[21] Abiero, P.O., et al. (2017) Influence of Marketing Strategies on Performance of Cultural Heritage Tourism in Kenya. European Journal of Business and Management, 9, 49-60.

[22] Bethapudi, A. (2013) The Role of ICT in Tourism Industry. Journal of Applied Economics and Business, 1, 67-79.

[23] Ayed Al qeed, M., Bazazo, I.K., Hasoneh, A.I. and Al Qaid, B.A. (2014) Using Geographic Information System to Visualize Travel Patterns and Market Potentials of Petra City in Jordan. International Journal of Marketing Studies, 2, 144-159. https://doi.org/10.5539/ijms.v2n2p144 
[24] Wei, W. (2012) Research on the Application of Geographic Information System in Tourism Management. Procedia Environmental Sciences, 12, 1104-1109. https://doi.org/10.1016/j.proenv.2012.01.394

[25] Maiti, A., Majumdar, S., Shukla, S., Koti, S.R. and Gupta, P.K. (2018) An Open Source Web-GIS Based Precise Satellite Tracking and Visualisation Tool Using Two Line Element Data. The ISPRS Annals of the Photogrammetry, Remote Sensing and Spatial Information Sciences, 4, 109-114.

https://doi.org/10.5194/isprs-annals-IV-5-109-2018

[26] Ayeni, O. (2006) A Multimedia GIS Database for Planning Management and Promotion of Sustainable Tourism Industry in Nigeria. Proceedings 33 th FIG Congress, Munich, 8-13 October 2006, 1-17.

[27] Sharma, N. (2016) Development of Web-Based Geographic Information System (GIS) for Promoting Tourism in Sivasagar District. International Journal of Innovation and Scientific Research, 24, 144-160.

[28] Unel, F.B., Gundogdu, I.B. and Yalpir, S. (2014) The Impact of Multimedia Geographic Information System in Tourism. International Journal of Computer Theory and Engineering, 7, 81-85. https://doi.org/10.7763/IJCTE.2015.V7.935

[29] Pispidikis, I. and Dimopoulou, E. (2015) Web Development of Spatial Content Management System through the Use of Free and Open-Source Technologies. Case Study in Rural Areas. Journal of Geographic Information System, 7, 527-540. https://doi.org/10.4236/jgis.2015.75042

[30] Zerihun, M.E. (2017) Web Based GIS for Tourism Development Using Effective Free and Open Source Software Case Study: Gondor Town and Its Surrounding Area, Ethiopia. Journal of Geographic Information System, 9, 47-58. https://doi.org/10.4236/jgis.2017.91004

[31] Almer, A. and Stelzl, H. (2002) Multimedia Visualization of Geoinformation for Tourism Regions Based on Remote Sensing Data. Earth.

[32] Kumar, P. and Kumar, D. (2016) Network Analysis Using GIS Techniques: A Case of Chandigarh City. International Journal of Science and Research, 5, 409-411. https://doi.org/10.21275/v5i2.NOV161143

[33] Sharma, O., Mioc, D. and Dharmaraj, G. (2005) Traveling Salesperson Approximation Algorithm for Real Road Networks. Proceedings of International Symposium on Spatio-Temporal Modeling, Spatial Reasoning, Analysis, Data Mining and Data Fusion.

http://www.isprs.org/proceedings/XXXVI/2-W25/source/TRAVELING_SALESPER SON_APPROXIMATION_ALGORITHM_FOR_REAL_ROAD.pdf

[34] Ardiansyah and Rainis, R. (2015) A PostgreSQL/PostGIS Implementation for the Sightseeing Tour Planning Problem. Jurnal Rekayasa Elektrika, 10, 115-119.

[35] Gu, W., Liu, Y., Wei, L.-R. and Dong, B.-K. (2015) A Hybrid Optimization Algorithm for Traveling Salesman Problem Based on Geographical Information System for Logistics Distribution. International Journal of Grid and Distributed Computing, 8, 359-370. https://doi.org/10.14257/ijgdc.2015.8.3.33

[36] Abubakar, E.O., Idoko, O. and Ocholi, O.S. (2017) Efficient Tour Planning for Tourist Sites Visitation in Lokoja, Nigeria: A Multi-Scenario Analysis Using GIS. Journal of Geographic Information System, 9, 59-81.

https://doi.org/10.4236/jgis.2017.91005

[37] Wijesinghe, K.D.K.D., Delpachithra, C.N., Perera, L.K.C.T., Wijetilake, S.H., Rajapaksha, S. and Fernando, N. (2013) GIS Enabled Travel Planner System with TSP Implementation. PNCTM, 2, 49-55. 
[38] Kumar, P. (2014) Internet Marketing in Tourism. 1-5.

[39] Facebook Newsroom (2019) Company Info. Facebook Newsroom. https://newsroom.fb.com/company-info

[40] Önder, I., Gunter, U. and Gindl, S. (2020) Utilizing Facebook Statistics in Tourism Demand Modeling and Destination Marketing. Journal of Travel Research, 59, 195-208. https://doi.org/10.1177/0047287519835969

[41] QGIS 3.8.1 (2019) Welcome to the QGIS Project! https://qgis.org/en/site

[42] pgAdmin 4 (2019) PostgreSQL: File Browser. https://www.postgresql.org/ftp/pgadmin/pgadmin4/v4.8/windows

[43] Geoserver (2019) GeoServer. http://geoserver.org

[44] Leaflet (2019) Leaflet-A JavaScript Library for Interactive Maps. https://leafletjs.com

[45] Cochran, W.G. (1977) Stratified Random Sampling, Further Aspects of Stratified Sampling.

[46] Geofabrik (2018) Geofabrik Download Server. http://download.geofabrik.de/africa/kenya.html

[47] World Resources Institute (2017) Kenya GIS Data. https://www.wri.org/resources/data-sets/kenya-gis-data\#tourism

[48] Kenya Wildlife Services (2018) Photo_store. Kenya Wildlife Service. https://www.kws.go.ke/photo-store

[49] PostgresSQL (2019) PostgreSQL: File Browser. https://www.postgresql.org/ftp/pgadmin/pgadmin4/v4.0/windows

[50] PgRouting (2019) pgRouting Project-Open Source Routing Library. https://pgrouting.org

[51] Kirono, S., Arifianto, M.I., Putra, R.E., Musoleh, A. and Setiadi, R. (2018) Graph-Based Modeling and Dijkstra Algorithm for Searching Vehicle Routes on Highways. International Journal of Mechanical Engineering \& Technology, 9, 1273-1280.

[52] Lloyd, E.K., Bondy, J.A. and Murty, U.S.R. (2007) Graph Theory with Applications. The Mathematical Gazette, 62, 63. https://doi.org/10.2307/3617646

[53] Papadimitriou, C.H. and Vazirani, U.V. (2006) Algorithms.

[54] Graphhoper (2019) Developers-GraphHopper Directions API. https://www.graphhopper.com/developers

[55] CS Min of Tourism (2019) Ministry of Tourism and Wildlife. http://www.tourism.go.ke/tourism-principal-secretary-joe-okudo-welcomes-kenyaairways-return-flight-kq003-from-new-york-to-nairobi

[56] Business Daily (2019) Direct US Flights a Game Changer for Kenya's Tourism-Business Daily.

https://www.businessdailyafrica.com/analysis/columnists/Direct-US-flights-a-game -changer-for-Kenya-s-tourism/4259356-4815618-bin28x/index.html

[57] KNBS (2018) Kenya Economic Survey 2018 Highlights Economic Survey 2018, No. April.

[58] Mutinda, R. and Mayaka, M. (2012) Application of Destination Choice Model: Factors Influencing Domestic Tourists Destination Choice among Residents of Nairobi, Kenya. Tourism Management, 33, 1593-1597. https://doi.org/10.1016/j.tourman.2011.12.008

[59] Brach, M. and Górski, D. (2014) Application of Network Analysis for Development 
and Promotion of Sustainable Tourism in Public Forests. Folia Forestalia Polonica Seria $A, 56,105-112$. https://doi.org/10.2478/ffp-2014-0010

[60] Singh, A.P. and Goyal, S. (2015) Web Enabled GIS Based Navigation Information System Using Network Analysis Capability.

[61] Google Maps. 2020. https://www.google.co.ke/maps/@-1.0987706,37.0078127,15z

[62] Google Earth. 2020.

https://earth.google.com/web/@-1.47503342,22.44933783,1386.83552741a,22250367 $.03265429 \mathrm{~d}, 35 \mathrm{y}, 355.24065359 \mathrm{~h}, 0 \mathrm{t}, 0 \mathrm{r}$ 